\title{
REJEIÇÃO HIPERAGUDA APÓS TRANSPLANTE PULMONAR UNILATERAL: RELATO DE CASO
}

\author{
Hyper-acute rejection following single lung transplantation: a case report \\ Marcos Naoyuki Samano', Mauro Canzian², Rogério Souza', Paulo Manuel Pêgo-Fernandes', Fabio Biscegli Jatene'
}

\begin{abstract}
RESUMO
Introdução: A falência imediata do enxerto em decorrência de rejeição hiperaguda é um fenômeno conhecido em transplantes cardíacos, renais e hepáticos. No transplante pulmonar é uma ocorrência rara, havendo poucos casos descritos na literatura internacional. Objetivo: Descrevemos o caso de um paciente submetido a transplante pulmonar unilateral por doença pulmonar obstrutiva crônica, que evoluiu com rejeição hiperaguda fatal, poucas horas após a operação. Métodos: Paciente masculino, 36 anos, portador de doença pulmonar obstrutiva crônica grave, com indicação para transplante pulmonar e cuja avaliação inicial evidenciava painel reativo de anticorpos. Este se tornou positivo após transfusões sangüíneas. Foi submetido a transplante unilateral esquerdo sem intercorrências, porém, apresentou rápida deterioração dos parâmetros ventilatórios, com progressiva infiltração radiográfica até completa opacificação do pulmão transplantado. A despeito da otimização dos parâmetros, o paciente faleceu nove horas após o transplante. Não houve possibilidade de realização de plasmaférese. Resultado: As análises histopatológica e imunohistoquímica evidenciaram sinais de rejeição hiperaguda, através de intensa deposição de fibrina, infiltrado neutrofílico exuberante e forte positividade ao fibrinogênio à imunofluorescência, sinais esses, ausentes na lesão de isquemia-reperfusão. Conclusão: Embora a rejeição hiperaguda tenha menor incidência no transplante pulmonar, é uma complicação grave e fatal. A realização do painel reativo de anticorpos é fundamental para se estabelecer rapidamente uma terapêutica agressiva de imunossupressão.
\end{abstract}

Descritores: Transplante de Pulmão, Rejeição de Enxerto, Imunossupressão, Plasmaférese, Imunohistoquímica.

Instituição:

1. Disciplina de Cirurgia Torácica e Disciplina de Pneumologia - Departamento de Cardiopneumologia da FMUSP

2. Laboratório de Anatomia Patológica do Instituto do Coração (InCor) - HC/FMUSP Instituto do Coração (InCor) HC/FMUSP

\section{Correspondência:}

Marcos Naoyuki Samano

Av. Dr. Enéas Carvalho Aguiar, 44

CEP 05403-000 - São Paulo SP Brasil

Tel.: 5511 3069-5248 - Fax: 5511 3069-5351

E-mail: marcos.samano@incor.usp.br

Recebido em: 14.08 .2006

Aceito em: 17.09.2007

\section{INTRODUÇÃO}

A rejeição hiperaguda é uma reação imediata do hospedeiro ao enxerto, que ocorre em decorrência de anticorpos pré-formados (IgG) que reagem contra receptores HLA classe I do órgão transplantado. Ocorre nas primeiras horas após o transplante, com a ativação do sistema complemento e destruição vascular. É um fenômeno bem estabelecido no transplante renal e cardíaco sendo pouco conhecido nos transplantes pulmonares, havendo poucos casos relatados na literatura mundial.

\section{RELATO DE CASO}

Paciente masculino, 36 anos, portador de doença pulmonar obstrutiva crônica (DPOC) e seqüela pulmonar por tuberculose, apresentando progressiva deterioração dos parâmetros ventilatórios, sendo incluído em lista de espera para transplante pulmonar. Seu painel reativo de anticorpos era negativo, mas tornou-se maior do que $10 \%$ após transfusões sangüíneas. Este resultado não chegou ao nosso conhecimento antes do transplante unilateral esquerdo que foi realizado sem intercorrências, com tempo de isquemia de 270 minutos e anastomose brônquica por telescopagem. A imunossupressão iniciou-se através de azatioprina pré-operatória, ciclosporina, e metilprednisolona. 
Encaminhado à Unidade de Terapia Intensiva, apresentava-se hemodinamicamente estável, com pequeno infiltrado perivascular. Houve rápida deterioração da função respiratória, com progressiva infiltração pulmonar evoluindo com completa opacificação poucas horas após o transplante (Figura 1). Apesar da otimização dos parâmetros ventilatórios com aumento de FiO2 e PEEP, o paciente faleceu nove horas após o transplante.
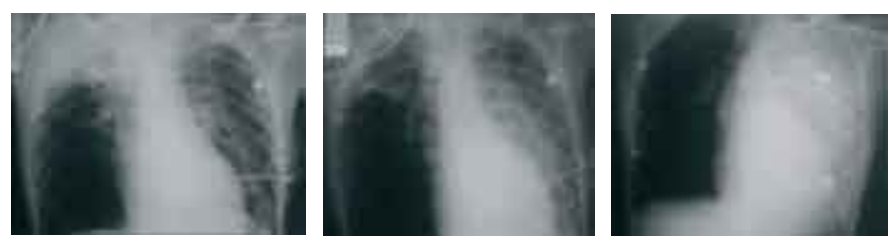

Figura 1: Radiografia de tórax pós-operatória onde observa-se pequena congestão pulmonar peri-hilar (A). No decorrer de poucas horas, houve progressivo infiltrado pulmonar (B), culminando com infiltração maciça do pulmão $(C)$ nove horas após o transplante.

A necrópsia não evidenciou complicações relacionadas às anastomoses. Macroscopicamente, observou-se congestão do pulmão, cujo parênquima adquirira aspecto hepatizado. Além de edema pulmonar, evidenciaram-se também lesões petequiais (Figura 2). Microscopicamente, não havia sinais de lesão de isquemia-reperfusão, tendo sido identificados: infiltrado intersticial neutrofílico difuso e acúmulo focal de neutróficos em alvéolos, edema, hemorragia e congestão vascular aguda com a presença de alguns trombos de fibrina nas arteríolas, além de deposição de fibrina alveolar (Figura 3). A análise por imunofluorescência revelou forte positividade para fibrinogênio, indicando ativação do sistema imunológico, embora houvesse positividade apenas leve e focal para IgM e C3. Não se observou positividade para IgG (Tabela 1).

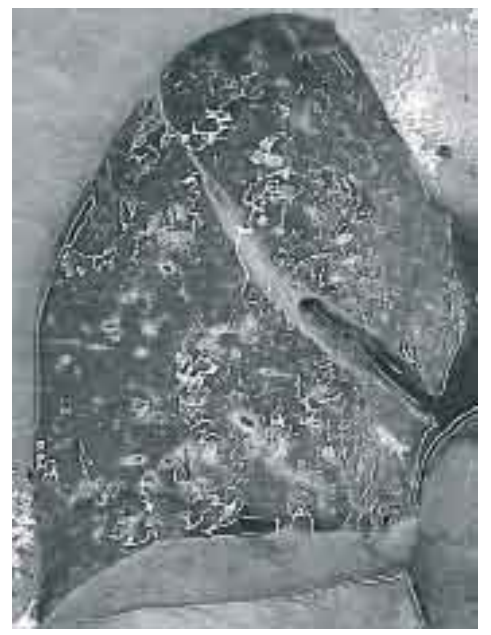

Figura 2: Aspecto post-mortem do pulmão transplantado, hepatizado, às custas de edema e congestão vascular.

\section{DISCUSSÃO}

O protótipo de rejeição hiperaguda é observado nos xenotransplantes experimentais. Nestes, células, tecidos ou órgãos são transplantados

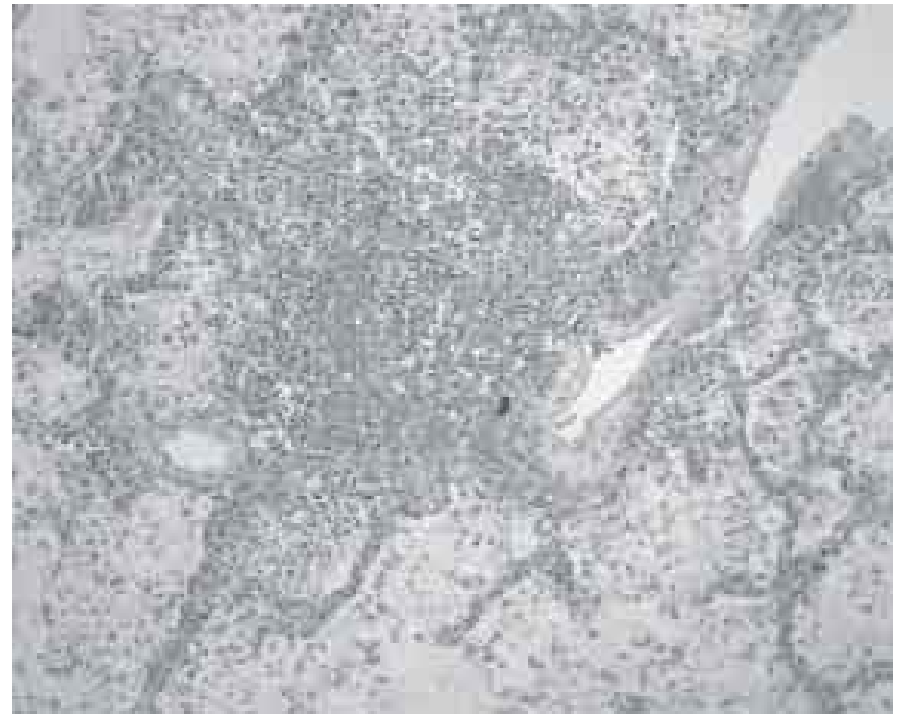

Figura 3: Microscopicamente, nota-se padrão de congestão aguda e acúmulo difuso de fibrina nos espaços alveolares. Há intenso infiltrado neutrofílico intersticial e também focos de hemorragia alveolar.

Tabela 1: A forte positividade para fibrinogênio através da análise por imunofluorescência indica ativação do sistema imunológico. O mesmo indica a positividade para IgM e C3, apesar de terem sido leves e focais.

\begin{tabular}{lllc}
\hline \multicolumn{3}{c}{ Análise por imunofluorescência } \\
\hline Septos alveolares & Vasos & Brônquios \\
\hline $\operatorname{lgM}$ & Focal + & Negativo & Negativo \\
$\operatorname{lgG}$ & Negativo & Negativo & Negativo \\
C3 & Focal + & Negativo & Negativo \\
Fibrinogênio & +++ & +++ & +++ \\
\hline
\end{tabular}

entre indivíduos de espécies diferentes. Anticorpos naturais presentes na circulação identificam-se e se ligam rapidamente a antígenos de superfície do enxerto, causando ativação do sistema complemento, ativação endotelial, apoptose, trombose e, por fim, a necrose isquêmica do órgão. Em primatas e porcos, a rejeição hiperaguda parece estar relacionada à presença do antígeno $\alpha$-Gal ( $\alpha$-1,3-galactosiltransferase) na superfície das células, sendo completamente dependente da ativação do sistema complemento.

De maneira semelhante, a rejeição hiperaguda pode ser observada na prática clínica, sendo bem documentada no transplante renal. É desencadeada pela presença de aloanticorpos preexistentes na circulação sangüínea do receptor, que rapidamente se ligam ao endotélio vascular do enxerto causando ativação do sistema complemento. Essa ativação desencadeia um processo de lesão celular endotelial, com exposição das proteínas da membrana basal e, conseqüentemente, ativação das plaquetas que se aderem e se agregam, formando trombos intramurais que ocasionam oclusão vascular e lesão isquêmica irreversível. Além disso, as células endoteliais perdem as proteoglicanas da superfície endotelial que poderiam interagir com a antitrombina III, inibindo a coagulação. 
O melhor exemplo de aloanticorpos são aqueles dirigidos contra antígenos do sistema sangüíneo ABO. Como a compatibilidade ou mesmo a igualdade do sistema $\mathrm{ABO}$ é condição absoluta para a realização do transplante, a rejeição hiperaguda decorrente de antígenos ABO não é observada. A exposição prévia a antígenos, geralmente após transfusões sangüíneas prévias, gestações múltiplas ou transplante prévio, pode predispor à formação de anticorpos circulantes que, dependendo de sua titulação, desencadeiam o processo de rejeição imediato.

Para diminuir os riscos de rejeição, realiza-se uma triagem em busca de anticorpos pré-formados, denominada painel reativo de anticorpos (PRA). O plasma do receptor reage contra um painel de doadores (representativos da população) e a ligação de anticorpos presentes nesse plasma à célula do doador representa $\mathrm{a}$ presença de anticorpos reativos. Esse resultado é dado na forma de percentagem, e a presença de PRA maior que $10 \%$ representa um risco ao desenvolvimento de rejeição hiperaguda. Esse resultado indica necessidade da realização do teste de compatibilidade cruzada ou crossmatching prévio (prospectivo) ao transplante. Para PRA menor que $10 \%$, realiza-se o teste de compatibilidade independentemente do transplante (retrospectivo).

A importância do PRA como medida de rastreamento para rejeição hiperaguda foi observada no primeiro caso relatado, em 1996. Naquela ocasião, o painel reativo de anticorpos foi de 16\%, 33\% e $11 \%$. Imediatamente após o transplante, houve saída de secreção pela cânula de intubação, piora radiológica e diminuição dos níveis de oxigenação. Após o resultado do teste de compatibilidade cruzada (crossmatching) positivo, iniciou-se plasmaférese e ciclofosfamida, mas o paciente evoluiu com coagulopatia de consumo e trombocitopenia, falecendo no décimo dia pós-operatório.

A rejeição hiperaguda após transplantes pulmonares é pouco relatada, tendo sido descritos poucos casos desde então $0^{4,5,6}$. Como os pacientes nefropatas crônicos e cardiopatas estão sujeitos a inúmeras transfusões sangüíneas prévias, estes estão mais sujeitos à sensibilização por antígenos do que pneumopatas crônicos submetidos a transplante.

Nas primeiras horas após o transplante, a rápida piora dos padrões ventilatórios pode ter duas causas principais: lesão de isquemia- reperfusão ou rejeição hiperaguda. Além dos dados obtidos através do perfil imunológico (PRA) e do crossmatching, que podem sugerir possibilidade de rejeição hiperaguda, os achados histopatológicos e o padrão imunohistoquímico podem diferenciála da lesão de isquemia-reperfusão. Esta última caracteriza-se por edema perivascular e peribrônquico, além de pequeno infiltrado neutrofílico que pode estar presente somente após 24 horas ${ }^{4}$. Já na rejeição hiperaguda há, além do edema pulmonar e congestão, intensa hemorragia alveolar, extravazamento de fibrina, infiltrado intersticial neutrofílico exuberante e trombos intramurais plaquetários e de fibrina. A análise imunohistoquímica mostra positividade para fibrinogênio e IgG ao longo dos septos e espaços alveolares, indicando ativação do sistema imune ${ }^{3}$.

A terapia agressiva de imunossupressão, através da indução e plasmaférese são as únicas formas de tratamento observadas nestes casos graves. Adotando-se técnicas semelhantes às adotadas na rejeição hiperaguda após transplantes cardíacos, relatou-se a utilização de plasmaférese (para diminuir a quantidade de anticorpos existentes), ciclofosfamida e imunoglobulina antitimocítica com sucesso e recuperação total do enxerto .

\section{CONCLUSÃO}

Apesar de não ter ocorrido expressão de marcadores para IgG no pulmão transplantado, a análise histológica e a forte positividade de fibrinogênio são suficientes para indicar presença de rejeição hiperaguda no caso relatado. Além disso, o painel reativo de anticorpos, positivo em mais do que $10 \%$, é um forte indício da evolução apresentada. Infelizmente, não tivemos acesso a este resultado antes do transplante.

Esta rejeição, causada por anticorpos pré-existentes por exposição prévia a antígenos, apresenta menor incidência no transplante pulmonar, possivelmente pelo fato de que pacientes pneumopatas são menos expostos a tais antígenos do que renais crônicos e cardiopatas graves. Entretanto, a realização de testes imunológicos através do painel reativo de anticorpos (PRA) e crossmatching são fundamentais para estabelecer rapidamente uma terapêutica agressiva de imunossupressão.

\section{ABSTRACT}

Introduction: Immediate graft failure due to hyper-acute rejection is an already known phenomenon in cardiac, renal and hepatic transplantation. It is a rare occurrence in lung transplantation, with few cases described in the international literature. Purpose: We described a case of single lung transplant due to Chronic Obstructive Pulmonary Disease which evolved to fatal hyper-acute rejection a few hours after the operation. Methods: A 36-year old male patient with Chronic Obstructive Pulmonary Disease and indication for lung transplantation, whose initial assessment showed a negative pane-reactive antibody, and became positive after blood transfusions. The patient was submitted to a one-sided left single-lung transplant with no intercurrence. However, he presented a fast deterioration of his breathing parameters, with progressive radiographic infiltration up to a complete opacification of the transplanted lung. The patient died nine hours following the transplantation, despite the optimization of the parameters. Results: Histopathological and immunohistochemical analysis revealed signs of hyper-acute rejection by an intense fibrin deposition, dense neutrophilic infiltrate, and strong positivity of the fibrinogen to the immunofluorescence, and these signs were not present in the ischemia-reperfusion lesion. Conclusion: Although the hyper-acute rejection has lower incidence in the lung transplantation, it represents a lethal and severe complication. The accomplishment of the panel-reactive antibody is very important to quickly establish an aggressive immunossupressant therapy.

Keywords: Lung Transplantation, Graft Rejection, Immunosupression, Plasmapheresis, Immunohistochemistry. 


\section{REFERENCES}

1. Waddell TK, Peterson MD. Xenotransplantation. Chest Surg Clin N Am. 2003;13:559-76.

2. Abbas AK, Lichtman AH. Imunologia do Transplante. In: Imunologia Celular e Molecular. Ed. Elsevier 2005; p. 379-9.

3. Frost AE, Jammal CT, Cagle PT. Hyperacute Rejection Following Lung Transplantation. Chest. 1996;110:559-62.

4. Choi JK, Kearns J, Palevsky HI, Montone KT, Kaiser LR, Zmijewski CM, Tomaszewski JE. Hyperacute Rejection of a Pulmonary Allograft. Immediate Clinical and Pathologic Findings. Am J Resp Crit Care Med. 1999;160:1015-8.
5. Zander DS, Baz MA, Visner GA, Staples ED, Donnelly WH, Faro A, Scornik JC. Analysis of Early Deaths After Isolated Lung Transplantation. Chest. 2001;120:225-32.

6. Kpodonu J, Massad MG, Chaer RA, Caines A, Evans A, Snow NJ and Geha AS. The US Experience with Lung Transplantation for Pulmonary Lymphangioleiomyomatosis. The Journal of Heart and Lung Transplantation. $2005 ; 24: 1247-53$.

7. Bittner HB, Dunitz J, Hertz M, Bolmann III MR, Park SJ. Hyperacute Rejection in Single Lung Transplantation - Case Report of Successful Management by Means of Plasmapheresis and Antithymocyte Globulin Treatment. Transplantation. 2001;71:649-51. 